\title{
Fisiopatologia das diarréias em suínos
}

\author{
Pathophysiology of swine diarrhea
}

Fábio Augusto Vannucci ${ }^{\mathrm{I}}$ Roberto Maurício Carvalho Guedes ${ }^{\mathrm{I}^{*}}$

\section{- REVISÃO BIBLIOGRÁFICA -}

\section{RESUMO}

A diarréia é a principal manifestação clínica das infecções entéricas. $O$ desequilíbrio entre os processos de absorção e secreção intestinal decorrentes de alterações no transporte de água e eletrólitos é determinante na patogênese dos processos diarréicos. Os mecanismos fisiopatológicos estão associados às características particulares de cada patógeno. Dessa forma, a interação específica entre os patógenos entéricos e o epitélio intestinal resulta em diferentes tipos de diarréias. Na produção de suínos, o conhecimento da fisiopatologia das infecções entéricas é fundamental no desenvolvimento de métodos de diagnóstico e, em um futuro próximo, na elaboração de estratégias de prevenção e controle dessas afecções. Com base nos processos fisiológicos característicos do trato gastrointestinal, esta revisão tem como objetivo descrever aspectos relevantes e atuais dos mecanismos fisiopatológicos das diarréias em suínos. Serão enfatizadas as alterações patológicas no transporte intestinal de íons e nutrientes decorrentes da ação de patógenos entéricos importantes na produção suinícola.

Palavras-chave: suíno, infecções entéricas, diarréia, fisiopatologia.

\section{ABSTRACT}

Diarrhea is the main clinical manifestation of enteric infections. Imbalance between absorption and intestinal secretion process due to changes in the water and electrolytes transport is critical in the diarrheal diseases pathogenesis. The pathophysiological mechanisms are associated to specific characteristics of each pathogen. Therefore, specific interaction between enteric pathogens and intestinal epithelium result in different types of diarrhea. In swine production, the knowledge about the enteric infections pathophysiology is important for the development of diagnostic methods and, in a near future improvement of prevention and control strategies. The aim of this review is to describe different relevant aspects of the swine diarrhea pathophysiology based on the physiological processes typical of gastrointestinal tract. Pathological changes in the intestinal transport of ions and nutrients due to infectious relevant for swine production will be emphasized.

Key words: swine, enteric infections, diarrhea, pathophysiology.

\section{INTRODUÇÃO}

As infecções entéricas estão entre as doenças mais frequentes na produção suinícola, sendo responsáveis por importantes perdas e significativo impacto econômico no setor. Os prejuízos são representados por redução do ganho de peso, mortalidade e gastos com antibioticoterapia (McORIST, 2005). As infecções por Lawsonia intracellularis, Salmonella enterica sorotipo Typhimurium e Brachyspira spp. estão entre as mais prevalentes no Brasil, nos Estados Unidos e na Europa, em suínos, nas fases de recria e terminação. (STEGE et al., 2000; BACCARO et al., 2003; SUH \& SONG, 2005). Algumas doenças entéricas de suínos podem acometer o homem, sobretudo por meio de infecções alimentares. Os principais agentes envolvidos nesses casos são

'Departamento de Clínica e Cirurgia Veterinárias, Escola de Veterinária, Universidade Federal de Minas Gerais (UFMG). Av. Antônio Carlos, 6627, Pampulha, 30123-970, Belo Horizonte, MG, Brasil. E-mail: guedes@vet.ufmg.br. *Autor para correspondência. 
Salmonella enterica e Escherichia coli enterotoxigênica (HALL et al., 2005; TURNER et al., 2006). Destaca-se ainda que as similaridades das lesões e da patogênese dessas infecções em suínos e humanos permitem o desenvolvimento de modelos experimentais, nos primeiros, para estudos da fisiopatologia dessas enfermidades (SAIF et al., 1997).

Os mecanismos determinantes para manifestação clínica das infecções entéricas resultam primariamente de alterações fisiológicas no transporte intestinal de água e eletrólitos (ARGENZIO, 1992). O desequilíbrio entre os mecanismos absortivos, secretórios e regulatórios inerentes ao epitélio intestinal promove expressiva perda de fluidos e compromete a absorção de nutrientes.

Esta revisão tem como objetivo apresentar os mecanismos fisiopatológicos das diarréias em suínos.

\section{Transporte intestinal de água e eletrólitos}

A mucosa intestinal, revestida por epitélio simples colunar, é responsável pela secreção e absorção de água, eletrólitos e nutrientes. Essa camada simples está constantemente exposta a fatores exógenos, presentes no lúmen intestinal (p.ex. nutrientes e patógenos), e sob influência de fatores intrínsecos do organismo, a partir da submucosa (p. ex. peptídeos ativos, hormônios e mediadores inflamatórios) (JONES \& BLIKSLAGER, 2002). Nesse contexto, o epitélio intestinal representa uma barreira seletiva regulada por mecanismos de transporte específicos e por junções intercelulares (tight junctions) (BERKES et al., 2003).

As principais células envolvidas no transporte de íons e nutrientes por meio da mucosa intestinal são os enterócitos maduros e as células das criptas intestinais (criptas de Lieberkühn). Os enterócitos maduros, presentes no ápice das vilosidades, são responsáveis pela absorção de nutrientes. As dissacaridases e peptidases são continuamente expressas na membrana apical dessas células e, por meio da hidrólise de carboidratos e proteínas da dieta, absorvem monossacarídeos, aminoácidos e peptídeos (HOLT \& YEH, 1992). A atividade secretora dessas células é mínima, entretanto pode ser estimulada por toxinas e neurotransmissores (JONES \& BLIKSLAGER, 2002). As células das criptas representam o compartimento proliferativo, que originará enterócitos maduros e diferenciados. Essas células imaturas presentes na base das vilosidades têm fundamental importância no processo de renovação celular, característico da mucosa do trato digestório. Possuem também predominantemente funções secretórias por meio de canais iônicos (WELSH et al., 1982). Portanto, alterações nos mecanismos de absorção e na secreção intestinal estão associadas às características específicas do patógeno em colonizar diferentes regiões das vilosidades.

\section{Mecanismos absortivos}

O íon $\mathrm{Na}^{+}$é o principal eletrólito envolvido nos processos de absorção intestinal. Baixas concentrações de $\mathrm{Na}^{+}$intracelular permitem o transporte por meio da membrana apical de carboidratos, aminoácidos, peptídeos e vitaminas hidrossolúveis. Os mecanismos de absorção desses nutrientes envolvem a ativação de transportadores acoplados ao $\mathrm{Na}^{+}$(WRIGHT, 1993).

O exemplo clássico é o transporte de glicose acoplado ao $\mathrm{Na}^{+}$pelo cotransportador $\mathrm{Na}^{+} /$glicose (SGLT1). A ativação desse mecanismo permite a absorção de duas moléculas de $\mathrm{Na}^{+}$para cada molécula de glicose, carreando água, por osmose, por meio das junções intercelulares. Em seguida, a glicose é transportada na membrana basolateral, por difusão facilitada, e o $\mathrm{Na}^{+}$, por ativação da bomba de sódio e potássio $\left(\mathrm{Na}^{+} / \mathrm{K}^{+}\right.$ATPase) (WRIGHT \& LOO, 2000). Esse é o principio básico da re-hidratação oral em casos de diarréia. A hidratação com soluções contendo glicose estimula a absorção de $\mathrm{Na}^{+}$e água, assim, essas soluções são mais eficientes que soluções salinas ( $\mathrm{NaCl}$ 0,9\%) (ARGENZIO, 1980). Agalactose é absorvida por esse mesmo processo. Contudo, a absorção de frutose ocorre por transportador específico (GLUT5), sem a necessidade de acoplagem com o $\mathrm{Na}^{+}$(RUMESSEN, 1992). Cotransportadores acoplados ao $\mathrm{Na}^{+}$também estão associados à absorção de aminoácidos, porém na proporção de 1:1.

O mecanismo mais importante na absorção intestinal de $\mathrm{Na}^{+}$ocorre por meio de trocas iônicas com íons $\mathrm{H}^{+}$realizadas por transportadores NHE. O acionamento desse mecanismo ocorre simultaneamente à ativação de transportadores $\mathrm{Cl}^{-} / \mathrm{HCO}_{3}^{-}$, os quais permitem a transferência de íons $\mathrm{Cl}^{-}$para o meio intracelular em troca de $\mathrm{HCO}_{3}^{-}$para o lúmen intestinal. Portanto, como resultado desse processo dinâmico, ocorre absorção de $\mathrm{Na}^{+}$e $\mathrm{Cl}^{-}$associada à secreção de $\mathrm{H}^{+}$e $\mathrm{HCO}_{3}^{-}$(ZACHOS et al., 2005). Os transportadores NHE são regulados pela concentração intracelular de monofosfato de adenosina cíclico (AMPc) e pela ativação da proteína quinase A (PKA). Nesse sentido, toxinas bacterianas e processos inflamatórios que elevam a concentração intracelular de AMPc e, consequentemente, ativam a PKA, inibem a função dos NHE, estimulando os processos diarréicos (FORTE et al., 1992).

Ciência Rural, v.39, n.7, out, 2009. 
Mecanismos secretórios

Os processos secretórios do epitélio intestinal ocorrem predominantemente nas criptas de Lieberkühn. Os eletrólitos envolvidos são $\mathrm{Cl}^{-}$e $\mathrm{HCO}_{3}^{-}$ (WELSH et al., 1982). A secreção de íons $\mathrm{Cl}^{-}$na membrana apical ocorre pela abertura de canais iônicos. O principal canal de $\mathrm{Cl}^{-}$é o regulador transmembrana da fibrose cística (CFTR). O nome dado refere-se à expressão anormal do gene codificador do CFTR em crianças com fibrose cística (ROGERS et al., 2008). Mensageiros intracelulares (AMPc e GMPc) regulam o funcionamento do CFTR por meio da ativação de proteínas quinases. Dessa forma, processos patológicos que resultam no aumento da concentração intracelular de AMPc promovem a ativação da PKA, abertura dos canais iônicos CFTR com consequente secreção de $\mathrm{Cl}^{-}$.

A concentração de íons $\mathrm{Ca}^{2+}$ presentes no citoplasma dos enterócitos é capaz de regular a abertura dos canais de $\mathrm{Cl}^{-}$dependentes de $\mathrm{Ca}^{2+}$ (CaCC). Pode ocorrer ainda sinergismo entre os mensageiros intracelulares, potencializando o estímulo secretório de $\mathrm{Cl}^{-}$(KEELY \& BARRETT, 2000).

Sistema nervoso entérico

O sistema nervoso entérico (SNE) é constituído por dois grandes plexos, submucoso e mioentérico, os quais são responsáveis pela regulação de estímulos motores e sensoriais. Esse sistema é capaz de coordenar o funcionamento do trato gastrointestinal e regular os mecanismos secretórios e absortivos pela ativação do sistema nervoso autônomo simpático e parassimpático (BENARROCH, 2007). A liberação de noradrenalina aciona mecanismos pró-absortivos pela ativação de receptores $\alpha 2$-adrenérgicos nos enterócitos (CHANG et al., 1982). Contrariamente, a acetilcolina e o peptídeo intestinal vasoativo (VIP) são os principais neurotransmissores envolvidos na estimulação dos processos secretórios. O SNE pode ser ativado por agentes tóxicos, estímulos endócrinos e mediadores inflamatórios, resultando no aumento da secreção intestinal (SPILLER, 2002). A estimulação local do SNE ocorre por arco reflexo. Nesse contexto, nervos sensoriais (via aferente) transmitem impulsos aos interneurônios (localizados nos plexo submucoso e mioentérico), os quais, por sua vez, comunicam-se com nervos motores (via eferente), promovendo liberação de neurotransmissores e peptídeos ativos (JONES \& BLIKSLAGER, 2002). O conhecimento dos mecanismos regulatórios do SNE envolvidos no transporte de eletrólitos pelo epitélio intestinal tem contribuído para o desenvolvimento de estratégias terapêuticas com a utilização de fármacos capazes de modular a resposta neurogênica.
Fisiopatologia das diarréias em suínos

Ao longo dos anos, as diarréias, nos animais domésticos, vêm sendo classificadas em quatro categorias: diarréia secretória, mal-absortiva, efusiva (inflamatória) e por hipermotilidade (MOON, 1978; ARGENZIO, 1992; FIELD, 2003; MOESER \& BLIKSLAGER, 2007). Na prática, as alterações patológicas envolvidas na diarréia secretória ou por má absorção também podem comprometer a integridade da mucosa e, por consequência, promover efusão de conteúdo protéico para o lúmen intestinal (RAMIG, 2004). Da mesma forma, processos inflamatórios entéricos caracterizados por intensas lesões tissulares podem ter um componente secretório envolvido na sua patogênese (GIANNELLA et al., 1975; GRONDAHL et al., 1998). Independentemente dos mecanismos fisiopatológicos, o aumento da motilidade intestinal ocorre secundariamente ao acúmulo de líquido no lúmen intestinal. Logo, a hipermotilidade certamente não possui função primária no desenvolvimento das diarréias infecciosas, nos animais domésticos (MOON, 1978; GREENWOOD \& DAVISON, 1987). Dessa forma, na presente revisão, a fisiopatologia das infecções entéricas em suínos será discutida a partir de três categorias: diarréia secretória, diarréia por má absorção e diarréia efusiva (inflamatória).

\section{Diarréia secretória}

A ativação súbita e descontrolada dos mecanismos secretórios da mucosa intestinal pode levar à desidratação intensa e, consequentemente, à morte. O principal íon envolvido na patogênese desse tipo de diarréia é o $\mathrm{Cl}^{-}$(FORTE et al., 1992). A diarréia secretória mais frequente entre os animais domésticos está associada à infecção por Escherichia coli enterotoxigênica (ETEC), sobretudo em leitões após o desmame e bezerros neonatos (NAGY \& FEKETE, 1999). Os dois principais fatores de virulência da ETEC são as fímbrias (adesinas) e as enterotoxinas. A partir da interação específica entre as fimbrias adesivas expressas na parede celular bacteriana com receptores presentes na membrana celular dos enterócitos, ocorre produção de enterotoxinas. Segundo MACEDO et al. (2007), as cepas F4 (K88), F18, F41 e F5 (K99) são as mais prevalentes no Estado de Minas Gerais. As enterotoxinas são divididas de acordo com sua estabilidade térmica: termolábeis (LT-I e LT-II) e termoestáveis (STa, STb e EAST1) (ZHANG et al., 2006). A ação dessas toxinas leva à ativação de mecanismos secretórios específicos no epitélio intestinal. 
As LTs são imunologicamente distintas entre si, no entanto têm mecanismos de ação semelhantes. Ambas possuem uma subunidade $\mathrm{B}$, que se liga ao receptor gangliosídeo (GM1) na membrana celular dos enterócitos, promovendo entrada da subunidade A, enzimaticamente ativa. A partir da clivagem dessa subunidade, formam-se dois domínios (A1 e A2) (SPANGLER, 1992). O domínio A1, presente no citoplasma celular, ativa a enzima adenilciclase, que catalisa a síntese de AMPc, que, por sua vez, ativa a PKA (HAMILTON et al, 1978; WIMER-MACKIN et al., 2001). Como consequência, ocorre fosforilação do CFTR e inibição do NHE na membrana apical, o que induz aumento significativo na secreção de $\mathrm{Cl}^{-}$e redução na absorção de $\mathrm{Na}^{+}$. Esse mecanismo também ocorre pela ação de enterotoxinas na cólera, em humanos (PETERSON \& WHIPP, 1995).

A toxina STa interage com receptor transmembrana guanilciclase tipo C (GC-C), promovendo o aumento da concentração intracitoplasmática de monofosfato de guanosina cíclico (GMPc). Esse evento ativa CFTR a partir da fosforilação da proteína quinase G (PKG) (GOLINBISELLO et al., 2005). Dessa forma, a ação da STa também resulta no aumento da secreção de íons $\mathrm{Cl}^{-}$e na inibição, na absorção de íons $\mathrm{Na}^{+}$(TIEN et al., 1994). A atividade biológica da EAST1 parece ser similar à atividade da STa. A partir da exposição da mucosa intestinal à EAST1, foi demonstrada elevação na concentração intracitoplasmática de GMPc (SAVARINO et al., 1993). Esses autores acreditam que haja similaridade estrutural entre essas duas toxinas.

A atividade da STb ainda é pouco compreendida; entretanto, sabe-se que não há envolvimento de nucleotídeos intracitoplasmáticos (AMPc ou GMPc), como ocorre na LT e STa (DUBREUIL, 2008). O estimulo secretório induzido pela ação da STb envolve a ativação do sistema nervoso entérico (PETERSON \& WHIPP, 1995). A protaglandina E2 e a 5-hidroxitriptamina (5-HT), secretadas a partir das células enteroendócrinas, são as principais mediadoras envolvidas nos mecanismos secretórios decorrentes da ação da toxina STb (DUBREUIL, 1999).

Nos estágios agudos da infecção por ETEC, não ocorre nenhum tipo de alteração histológica evidente, visto que a patogênese envolve mecanismos estritamente bioquímicos pela ação de enterotoxinas. Entretanto, secundariamente à perda de eletrólitos, pode ocorrer necrose isquêmica e atrofia de vilosidades em fases mais tardias (ROSE et al., 1987).

A colibacilose pós-desmame em suínos é atribuída a infecções por cepas de $\boldsymbol{E}$. coli produtoras de Shiga toxina (STx2e), que induzem a doença do edema (WADDELL et al, 1996). A aderência bacteriana à mucosa intestinal é mediada pela fimbria F18. Em seguida, ocorre liberação e migração transepitelial dessa toxina e, como consequência, degeneração e necrose do endotélio vascular, sinais neurológicos e edema em vários tecidos. No entanto, não há lesão na mucosa intestinal (WADDELL et al., 1998). A inoculação experimental de altas doses de STx2e no lúmen intestinal não reproduziu a doença (GANNON \& GYLES, 1990). Entretanto, WADDELL \& GYLES (1995), a partir da inoculação intragástrica de STx2e associada a um sal biliar (desoxicolato de sódio), que induz alterações na permeabilidade da barreira epitelial, conseguiram reproduzir a enfermidade. Dessa forma, esses autores sugerem que o aumento na permeabilidade da mucosa intestinal é pré-requisito para o desenvolvimento da doença do edema. NABUURS et al. (2001) demonstraram associação entre a acidose intestinal e a doença do edema. Contudo, a patogênese dessa possível interação ainda não foi esclarecida.

\section{Diarréia por má absorção}

A ação direta de patógenos entéricos sob o epitélio intestinal induz a lise celular. Nesses casos, a intensidade da infecção e a morte celular superam a capacidade de renovação epitelial, levando à atrofia de vilosidades e, consequentemente, à redução na absorção intestinal (MOON, 1978). As alterações nos mecanismos de absorção são decorrentes da perda e fusão de vilosidades com redução na produção de enzimas digestivas e inibição da atividade biológica dos transportadores de membrana (ARGENZIO, 1992). As alterações morfológicas observadas na mucosa intestinal são caracterizadas pela substituição de células colunares maduras por células cubóides em processo de diferenciação (REYNOLDS et al., 1985). A patogênese dessas infecções depende do local de replicação do agente nas vilosidades (ápice ou criptas).

A infecção pelo rotavírus é importante causa de diarréia em crianças e animais neonatos. O terço apical das vilosidades é o local de predileção para a replicação desse agente (SAIF et al., 1997). A replicação viral no citoplasma dos enterócitos promove liberação de íons $\mathrm{Ca}^{2+}$ a partir do retículo endoplasmático (BRUNET et al., 2000). O aumento de $\mathrm{Ca}^{2+}$ intracelular ativa uma série de mecanismos celulares, incluindo inibição da atividade do citoesqueleto nas microvilosidades, redução na expressão das dissacaridases e outras enzimas da superfície apical, inibição dos transportadores SGLT1 e necrose celular (PEREZ et al., 1998). Os principais eventos que comprometem a funcionalidade dos processos de absorção ocorrem pela redução da atividade do SGLT1 
e pela menor expressão de enzimas digestivas (dissacaridases) na superfície epitelial (HALAIHEL et al., 2000a). Com o aumento na permeabilidade da membrana celular, ocorre elevação de íons $\mathrm{Na}^{+}$e decréscimo de íons $\mathrm{K}^{+}$intracitoplasmáticos. Segundo CASTILLO et al. (1991), a alteração no equilíbrio dinâmico desses eletrólitos poderia comprometer a absorção de $\mathrm{NaCl}$ e a ativação de transportadores SGLT1, como consequência, haveria maior perda de água e eletrólitos.

Não há dúvida com relação à importância dos mecanismos de má absorção na rotavirose. No entanto, VELLENGA et al. (1992) observaram a presença de diarréia aquosa em suínos experimentalmente infectados, associada à ausência de lesões histológicas até 48 horas após a infecção, sugerindo envolvimento de mecanismos de secreção na patogênese dessa diarréia. Essa observação pode ser esclarecida a partir do reconhecimento de uma proteína não estrutural (NSP4) enterotoxigênica, produzida pelo rotavírus. A NSP4 atua como enterotoxina, a qual induz aumento da concentração intracelular de $\mathrm{Ca}^{2+} \mathrm{e}$, consequentemente, secreção de íons pelas criptas intestinais, mediada pela ativação de transportadores de $\mathrm{Cl}^{-}$(BALL et al., 1996). Nesse caso, o mecanismo de secreção não envolve AMPc, pois camundongos ausentes de CFTR foram susceptíveis à infecção por rotavírus e à indução de diarréia por inoculação da enterotoxina NSP4 (MORRIS et al., 1999). Nesse contexto, sugere-se o envolvimento dos canais de $\mathrm{Cl}^{-}$dependentes de $\mathrm{Ca}^{+}(\mathrm{CaCC})$ na patogênese dessa infecção. Ainda, a NSP4 tem pouco efeito na indução de diarréia em animais adultos, possivelmente pela baixa expressão de CaCC. Essa toxina também é capaz de inibir especificamente a atividade do SGLT1, o que contribui para má absorção intestinal (HALAIHEL et al., 2000b).

Comparativamente, a enterotoxina viral (NSP4) e as bacterianas possuem em comum a característica de não causarem lesões morfológicas na mucosa intestinal; entretanto, as enterotoxinas bacterianas não possuem efeito direto sobre o SGLT1. Ainda, a secreção de $\mathrm{Cl}^{-}$, na infecção por rotavírus, não é mediada por nucleotídeos (AMPc ou GMPc) e não envolve o CFTR, tal como ocorre nas diarréias por ETEC(LORROT\& VASSEUR, 2007).

Os mecanismos de ativação do sistema nervoso entérico (SNE), nas infecções por rotavírus, ainda não estão bem esclarecidos. Entretanto, não foi demonstrada experimentalmente a estimulação do SNE a partir da atividade biológica da NSP4 nas células das criptas (LUNDGREN et. al., 2000). Portanto, é possível que haja secreção de citocinas e protaglandinas por células infectadas presentes no terço apical das vilosidades, com posterior ativação do SNE e estimulação dos mecanismos secretórios nas células das criptas (CASOLA et al., 1998). Segundo LUNDGREN et. al. (2000), aproximadamente 67\% da atividade secretória, nas infecções por rotavírus, ocorre em decorrência da ativação do SNE. Os principais neurotransmissores envolvidos no estímulo secretório são a 5-HT e o VIP, indicando uma possível ativação de arco reflexo local (KORDASTI et al., 2004).

Diferentemente das infecções por rotavírus, o vírus da gastroenterite transmissível (coronavírus) acomete suínos em qualquer fase do sistema de produção, sendo capaz de replicar-se em enterócitos, em vários estágios de diferenciação e, por conseguinte, causar intensa atrofia de vilosidades. A diarréia por má absorção ocorre pela diminuição da atividade das enzimas (dissacaridases e peptidases) presentes nas microvilosidades do epitélio intestinal e pela redução na absorção de $\mathrm{Na}^{+}$e $\mathrm{Cl}^{-}$, semelhante aos mecanismos de má absorção induzidos pelo rotavírus (HOMAIDAN et al., 1991).

Algumas doenças entéricas bacterianas, importantes na produção de suínos, também podem provocar alterações nos processos absortivos da mucosa intestinal. As infecções por espiroquetas, Brachyspira hyodysenteriae e Brachyspira pilosicoli, estão entre as mais prevalentes e caracterizam-se por colites hemorrágicas e catarrais, respectivamente. A patogênese dessas infecções envolve mecanismos predominantemente mal-absortivos (ARGENZIO, 1980; SUH \& SONG, 2005). A infecção experimental $\operatorname{com} \boldsymbol{B}$. hyodysenteriae demonstrou significativa redução na absorção de água e $\mathrm{Na}^{+}$, na mucosa do cólon de suínos (ARGENZIO et. al., 1980).

A enteropatia proliferativa suína é uma doença entérica, causada pela bactéria intracelular obrigatória Lawsonia intracellularis. A primeira alteração observada na enteropatia proliferativa é a hiperplasia da mucosa intestinal com progressiva substituição de enterócitos maduros e colunares das vilosidades, por células pouco diferenciadas do epitélio das criptas intestinais (GUEDES et al., 2003). A alteração proliferativa está diretamente relacionada à infecção e replicação bacteriana. Entretanto, os mecanismos que promovem a hiperplasia da mucosa ainda não estão esclarecidos. Possivelmente, células imaturas hiperplásicas possuem reduzida expressão de proteínas e transportadores de membrana, comprometendo a capacidade de absorção. A diarréia por má absorção pode ser um dos principais fatores determinantes na redução do ganho de peso e no atraso no crescimento em suínos infectados. Contudo, ainda não são conhecidos os mecanismos fisiopatológicos 
causadores da diarréia na enteropatia proliferativa (MOESER \& BLIKSLAGER, 2007). PIDSUDKO et al. (2008) demonstraram a ativação de neurotransmissores no intestino de animais infectados; entretanto, não se sabe qual a atuação do sistema nervoso entérico na patogênese da doença.

A coccidiose por Isospora suis representa uma importante causa de diarréia em leitões entre sete e 20 dias de idade. As lesões ocorrem pela penetração de esporozoitos no citoplasma dos enterócitos com posterior lise celular. Atrofia e fusão de vilosidades associadas à enterite necrótica são as lesões histológicas mais observadas e constituem a principal causa da diarréia por má absorção. No entanto, infecções secundárias por ETEC são comuns e podem estimular mecanismos secretórios, contribuindo para o processo diarréico (CHAE et. al., 1998).

\section{Diarréia efusiva (inflamatória)}

Os mecanismos fisiopatológicos das diarréias inflamatórias podem ser discutidos considerando a infecção por Salmonella enterica sorotipo Typhimurium, responsável por enterocolites em humanos e animais, sendo capaz de invadir enterócitos e células M (SANTOS et al., 2002b). A penetração na célula hospedeira é determinada pela interação de vários fatores de virulência. O principal mecanismo de invasão está associado à ativação do sistema de secreção tipo III pela bactéria, que permite o transporte de proteínas bacterianas para o citoplasma do enterócito e a posterior indução do processo inflamatório (GALYOV et al., 1997). Alguns autores demonstraram ativação dos mecanismos secretórios determinada pelo acúmulo de líquido no lúmen intestinal após a infecção experimental com S. enterica Typhimurium (GIANNELLA et al., 1975; GRONDAHL et al., 1998). Contudo, a utilização de bovinos como modelo experimental demonstrou o envolvimento primário de mecanismos inflamatórios com significativa contribuição para perda de líquido durante a enterocolite (SANTOS et al., 2002a). A invasão de $\boldsymbol{S}$. enterica, em cultura de células epiteliais, aumentou a expressão e secreção de interleucina oito (IL-8), citocina envolvida na quimiotaxia de neutrófilos (ECKMANN et al., 1993). Dessa forma, a diarréia presente nas infecções por $\boldsymbol{S}$. enterica Typhimurium pode ser considerada nitidamente inflamatória e mediada predominantemente por neutrófilos. Os mecanismos secretórios, caracterizados pelo acúmulo de líquido no lúmen intestinal, poderiam ocorrer pelo aumento da permeabilidade do epitélio intestinal secundária ao processo inflamatório. A avaliação histopatológica de fragmentos intestinais de bovinos,
18 e 48 horas após a infecção oral com $\boldsymbol{S}$. enterica Typhimurium, revelou necrose da mucosa, difusa e acentuada, com perda completa do epitélio intestinal. As alterações anatomo-histopatológicas indicaram que o aumento da permeabilidade vascular associada à intensa infiltração inflamatória, com perda da integridade epitelial, poderia determinar a diarréia efusiva, caracterizada pela perda de água, por eletrólitos e por proteínas plasmáticas do sangue para o lúmen intestinal (TSOLIS et al., 1999).

As infecções por Clostridium difficile também estimulam acentuada resposta inflamatória; porém, mediada pela liberação de toxinas (A e B). A ação direta dessas toxinas no epitélio intestinal induz morte celular e intensa resposta inflamatória com liberação de citocinas (IL-8, TNFalfa e PGE2) pelas células do hospedeiro e posterior recrutamento de neutrófilos (CASTAGLIUOLO et al., 1994; SAVIDGE et al., 2003). A diarréia ocorre pela ativação de mecanismos inflamatórios, levando ao aumento da permeabilidade da barreira intestinal e, consequentemente, à perda de água, eletrólitos e proteínas, semelhante à salmonelose. HECHT et al. (1988) observaram, in vitro, que a toxina A, em contato com células epiteliais, promovem alterações estruturais no citoesqueleto e abertura das junções intercelulares. Esse fato poderia contribuir para o aumento da permeabilidade epitelial. O sistema nervoso entérico parece atuar no início do processo inflamatório sob a ação de citocinas pró-inflamatórias. Terminações nervosas sensoriais presentes na submucosa liberam neurotransmissores (substância P e peptídeo relacionado ao gene da calcitonina) que atuam em mastócitos, os quais contribuem para o recrutamento de neutrófilos (CASTAGLIUOLO et al., 1994).

O Clostridium perfringens tipo A e C são os agentes responsáveis por infecções entéricas e diarréias em leitões neonatos. As infecções causadas pelo $C$. perfringens tipo $C$, produtor das toxinas a e $\beta$, são mais graves que o tipo A(SONGER \& UZAL, 2005). As lesões causadas pelo tipo C ocorrem por ação direta sobre os enterócitos na região do jejuno e, por conseguinte, descamação, invasão e proliferação bacteriana a partir da membrana basal. Microscopicamente, podem ser observadas extensas áreas de necrose, envolvendo células das criptas, lâmina própria, submucosa e até camadas musculares (ARBUCKLE, 1972). Desse modo, mecanismos efusivos, caracterizados pela intensa perda de eletrólitos, proteínas e sangue para a luz intestinal, são determinantes na patogênese da diarréia. As infecções por $\boldsymbol{C}$. perfringens tipo A geralmente não são caracterizadas por lesões macro ou microscópicas. 
Eventualmente, pode-se observar presença de colônias bacterianas associadas à superfície apical dos enterócitos. Nesses casos, é possível que a diarréia esteja associada à ativação de mecanismos secretórios no epitélio intestinal mediado pelas toxinas $\alpha$ e $\beta 2$ (SONGER \& UZAL, 2005).

Diarréia persistente em animais de recria e terminação tem sido descrita como uma das manifestações clínicas nas infecções por circovírus suíno tipo 2 (KIM et al., 2004). As lesões são caracterizadas por infiltração inflamatória granulomatosa associada à intensa depleção linfóide nas placas de Peyer, podendo haver envolvimento de linfonodos mesentéricos (CHAE, 2005). A enterite granulomatosa, representada macroscopicamente por maior evidenciação das placas de Peyer e aumento de volume da cadeia de linfonodos mesentéricos, possivelmente compromete a drenagem linfática regional por meio da compressão de capilares linfáticos, promovendo efusão de fluido para o lúmen intestinal. Considerando a capacidade de imunossupressão desse patógeno, é provável que esse tipo de diarréia também envolva agentes bacterianos oportunistas (JENSEN et al., 2006). No entanto, a patogênese da enterite por circovirus suíno tipo 2 e os mecanismos fisiopatológicos determinantes para diarréia ainda não são conhecidos.

\section{CONCLUSÕES}

A partir da avaliação dos processos fisiopatológicos das principais infecções entéricas de suínos, é possível perceber a variedade de mecanismos envolvidos na indução das diarréias. As alterações no transporte de água e eletrólitos, o aumento da permeabilidade da barreira epitelial e a ativação de processos inflamatórios são os principais fatores determinantes na patogênese dessas enfermidades. No entanto, fica claro que esses fatores não atuam de forma isolada e estão constantemente sob influência local de outros mecanismos. A compreensão dos mecanismos fisiopatológicos predominantes e que efetivamente determinam o tipo de diarréia é fundamental para futura elaboração de estratégias de prevenção e controle dessas afecções em suínos. Em medicina humana, vem sendo demonstrado que o uso de probióticos pode diminuir diarréias virais, mas os mecanismos que governam esse efeito ainda são pouco conhecidos. Isso demonstra que ainda há um longo caminha a percorrer.

\section{REFERÊNCIAS}

ARBUCKLE, J.B.R. The attachment of Clostridium welchii (C. perfringens) type $\mathrm{C}$ to intestinal villi of pigs. Journal of Pathology, v.106, p.65-72, 1972.

ARGENZIO, R.A. Glucose-stimulated fluid absorption in the pig small intestine during the early stage of swine dysentery. American Journal Veterinary Research, v.41, p.20002006, 1980.

ARGENZIO, R.A. Pathophysiology of diarrhea. In: ANDERSON, N.V. Veterinary gastroenterology. Philadelphia: Lea \& Febiger, 1992. Cap.10, p.163-172.

ARGENZIO, R.A. et al. Pathophysiology of swine dysentery: colonic transport and permeability studies. Journal Infectious Diseases, v.142, p.676-684, 1980.

BACCARO, M.R. et al. Identification of bacterial agents of enteric diseases by multiplex PCR in growing-finishing pigs. Brazilian Journal Microbiology, v.34, p.225-229, 2003.

BALL, J.M. et al. Age-dependent diarrhea induced by a rotavirus nonstructural glycoprotein. Science, v.272, p.101-104, 1996.

BENARROCH, E.E. Enteric nervous system. Neurology, v.69, p.1953-1967, 2007.

BERKES, J. et al. Intestinal epithelial responses to enteric pathogens: effects on the tight junction barrier, ion transport, and inflammation. Gut, v.52, p.439-451, 2003. Disponível em: < http://gut.bmj.com/cgi/reprint/52/3/439>. Acesso em: 30 mar. 2009. doi: 10.1136/gut.52.3.439.

BRUNET, J.P. et al. Rotavirus infection induces an increase in intracellular calcium concentration in human intestinal epithelial cells: role microvillar actin alteration. Journal of Virology, v.74, p.2323-2332, 2000.

CASOLA, A. Rotavirus infection of cultured intestinal epithelial cells induces secretion of CXC and CC chemokines. Gastroenterology, v.114, p.947-955, 1998.

CASTAGLiUOLO, I. et al. Neuronal involvement in the intestinal effects of Clostridium difficile toxin A and Vibrio cholera enterotoxin in rat ileum. Gastroenterology, v.107, p.657-665, 1994.

CASTILLO, J.R. et al. Rotavirus infection alter $\mathrm{Na}^{+}$and $\mathrm{K}^{+}$ homeostasis in MA104 cells. Journal of General Virology, v.72, p.541-547, 1991.

CHAE, C. A review of porcine circovirus 2-associated syndromes and diseases. Veterinary Journal, v.169, p.326336, 2005. Disponível em: http://dx.doi.org/10.1016/ j.tvjl.2004.01.012. Acesso em: 30 mar. 2009. doi: 10.1016/ j.tvjl.2004.01.012.

CHAE, C. et al. Diarrhea in nursing piglets associated with coccidiosis: prevalence, microscopic lesions and coexisting microorganisms. Veterinary Record, v.143, p.417-420, 1998.

CHANG, E.B. et al. $\alpha 2$-Adrenergic receptor regulation of ion transport in rabbit ileum. American Journal Physiology, v.242, p. G237-G242, 1982. 
DUBREUIL, J.D. Escherichia coli STb toxin and prostaglandin production. Microbiology, v.145, p.1507-1508, 1999.

DUBREUIL, J.D. Escherichia coli STb toxin and colibacillosis: knowing is half the battle. FEMS Microbiology Letters, v.278, p.137-145, 2008. Disponível em: http:// www3.interscience.wiley.com/cgi-bin/fulltext/119404266/ PDFSTART>. Acesso em: 30 mar. 2009. doi: 10.1111/j.15746968.2007.00967.x

ECKMANN, L. et al. Epithelial cells secrete the chemokine interleukin-8 in response to bacterial entry. Infection and Immunity, v.61, p.4569-4574, 1993.

FIELD, M. Intestinal ion transport and the pathophysiology of diarrhea. Journal of Clinical Investigation., v.111, p.931-943, 2003. Disponível em: < http://www.jci.org/articles/ view/18326/pdf $>$. Acesso em: 30 mar. 2009. doi: 10.1172/ JCI18326

FORTE, L.R. et al. Stimulation of intestinal $\mathrm{Cl}^{-}$transport by heat-stable enterotoxin: activation of cAMP-dependent protein kinase by cGMP. American Journal Physiology, v.263, p.C607- C615, 1992.

GALYOV, E.E. et al. Secreted effector protein of Salmonella dublin is translocated into eukaryotic cells and mediates inflammation and fluid secretion in infected ileal mucosa. Molecular Microbiology, v.25, p.903-912, 1997.

GANNON, V.; GYLES, C. Characteristics of the Shiga-like toxin produced by Escherichia coli associated with porcine edema disease. Veterinary Microbiology, v.24, p.89-100, 1990.

GIANNELLA, R.A. et al. Pathogenesis of Salmonella-mediated intestinal fluid secretion. Activation of adenylate cyclase and inhibition by indomethacin. Gastroenterology, v.69, n.6, p.1238-1245, 1975.

GOLIN-BISELLO, F. et al. STa and cGMP stimulate CFTR translocation to the surface of villus enterocytes in rat jejunum and is regulated by protein kinase G. American Journal Physiology Cell Physiology, v.289, n.3, p.C708-C716, 2005.

GREENWOOD, B; DAVISON, J.S. The relationship between gastrointestinal motility and secretion. American Journal Physiology, v.252, p.G1-G7, 1987.

GRONDAHL, M.L. et al. Secretory pathways in Salmonella Typhimurium-induced fluid accumulation in the porcine small intestine. Journal of Medical Microbiology, v.47, n.2, p.151157, 1998.

GUEDES, R.M.C. et al. Relationship between the severity of porcine proliferative enterophaty and the infectious dose of Lawsonia intracellularis. Veterinary Record, v.153, p.432433, 2003.

HALAIHEL, N. et al. Rotavirus infection impairs intestinal brush-border membrane $\mathrm{Na}^{+}$-solute cotransport activities in young rabbits. American Journal Physiology. Gastrointestinal and Liver Physiology, v.279, p.G587-G596, 2000a.

HALAIHEL, N. et al. Direct inhibitory effect of rotavirus NSP4(114-135) peptide on the $\mathrm{Na}(+)$-D-glucose symporter of rabbit intestinal brush border membrane. Journal Virology, v.74, p.9464-9470, 2000b.

HALL, G. et al. Estimating foodborne gastroenteritis, Australia. Emerging Infectious Disease, v.11, n.8, p.1257-1264, 2005.

HAMILTON, D.L. et al. The effect of cholera toxin and heat labile and heat stable Escherichia coli enterotoxin on cyclic AMP concentrations in small intestinal mucosa of pig and rabbit. Canadian Journal Comparative Medicine, v.42, p.327-331, 1978.

HECHT G. et al. Clostridium difficile toxin A perturbs cytoesqueletal structure and tight junction permeability of culture human intestinal epithelial monolayers. Journal Clinical Investigation, v.82, p.1516-1524, 1988.

HOLT, P.R.; YEH, K.Y. Effects of starvation and refeeding on jejunal dissacaridase activity. Digestive Diseases and Science, v.37, p.827-832, 1992.

HOMAIDAN, F.R. et al. Electrolyte transport in piglets infected with transmissible gastroenteritis virus. Stimulation by verapamil and clonidine. Gastroenterology, v.101, p.895-901, 1991.

JENSEN, T.K. et al. Distinction between porcine circovirus type 2 enteritis and porcine proliferative enteropathy caused by Lawsonia intracellularis. Journal Comparative Pathology, v.135. p.176-182, 2006.

JONES, S.L.; BLIKSLAGER, A.T. Role of the enteric nervous system in the pathophysiology of secretory diarrhea. Journal Veterinary Internal Medicine, v.16, p.222-228, 2002.

KEELY, S.J.; BARRETT, K.E. Regulation of chloride secretion. Novel pathways and messengers. Annual New York Academic Science, v.915, p.67-76, 2000.

KIM, J. et al. Enteritis associated with porcine circovirus 2 in pigs. Canadian Journal Veterinary Research, v.68, p.218221, 2004.

KORDASTI, S. et al. Serotonin and vasoactive intestinal peptide antagonists attenuate rotavirus diarrhea. Gut, v.53, p.952957, 2004.

LORROT, M.; VASSEUR, M. How do the rotavirus NSP4 and bacterial enterotoxins lead differently to diarrhea? Virology Journal, v.4, n.31, p.1-6, 2007. Disponível em: <http://www.pubmedcentral.nih.gov/ picrender.fcgi?artid=1839081\&blobtype=pdf $>$. Acesso em: 30 mar. 2009. doi: 10.1186/1743-422X-4-31.

LUNDGREN, O. et al. Role of the enteric nervous system in the fluid and electrolyte secretion of rotavirus diarrhea. Science, v.287, p.491-495, 2000.

MACEDO, R.N. et al. Detecção de cepas patogênicas pela PCR multiplex e avaliação da sensibilidade a antimicrobianos de Escherichia coli isoladas de leitões diarréicos. Arquivo Brasileiro de Medicina Veterinária e Zootecnia, v.59, n.5, p.1117-1123, 2007.

McORIST, S. Defining the full costs of endemic porcine proliferative enteropathy. Veterinay Journal, v.170, n.1, p.8-9, 2005. Disponível em: <http://dx.doi.org/10.1016/ j.tvjl.2004.04.008>. Acesso em: 30 mar. 2009. doi: 10.1016/ j.tvjl.2004.04.008.

Ciência Rural, v.39, n.7, out, 2009. 
MOESER, A.M.; BLIKSLAGER, A.T. Mechanisms of porcine diarrhea. Journal American Veterinary Medical Association, v.231, n.1, p.56-67, 2007.

MOON, H.W. Mechanisms in the pathogenesis of diarrhea: a review. Journal American Veterinary Medical Association v.172, n.4, p.443-448, 1978.

MORRIS, A.P. et al. NSP4 elicits age-dependent diarrhea and Ca2+-mediated 1 influx into intestinal crypts of CF mice. American Journal Physiology, v.277, p.G431-G444, 1999.

NABUURS, M.J. et al. Oedema disease is associated with metabolic acidosis and small intestinal acidosis. Research Veterinary Science, v.70, p.247-253, 2001

NAGY, B.; FEKETE, P.Z. Enterotoxigenic Escherichia coli (ETEC) in farm animals. Veterinary Research, v.30, p.259284, 1999.

PEREZ, J. F. et al. Oncosis in MA104 cells is induced by rotavirus infection through an increase in intracellular $\mathrm{Ca}^{2+}$ concentration. Virology, v.252, p.17-27, 1998. Disponível em; <http://dx.doi.org/10.1006/viro.1998.9433>. Acesso em: 30 mar. 2009. doi: 10.1006/viro.1998.9433.

PETERSON, J.W.; WHIPP, S.C. Comparison of the mechanisms of action of cholera toxin and the heat-stable enterotoxins of Escherichia coli. Infection and Immunity, v.63, p.1452-1461, 1995.

PIDSUDKO, Z. et al. Distribution and chemical coding of intramural neurons in the porcine ileum during proliferative enteropathy. Journal Comparative Pathology, v.138, p.2331, 2008. Disponível em: <http://dx.doi.org/10.1016/ j.jcpa.2007.09.003>. Acesso em: 30 mar. 2009. doi: 10.1016/ j.jcpa.2007.09.003

RAMIG, R.F. Pathogenesis of intestinal and systemic rotavirus infection. Journal Virology, v.78, p.10213-10220, 2004 Disponível em: <http://jvi.asm.org/cgi/reprint/78/19/10213>. Acesso em: 30 mar. 2009. doi: 10.1128/JVI.78.19.1021310220.2004 .

ROGERS, C.S. et al. Disruption of the CFTR gene produces model of cystic fibrosis in newborn pigs. Science, v.321, p.18371841, 2008. Disponível em: <http://www.pubmedcentral.nih.gov/ picrender.fcgi ?artid $=2570747$ \&blobtype $=$ pdf $>$. Acesso em: 30 mar. 2009. doi: 10.1126/science.1163600.

ROSE, R. et al. Effects of Escherichia coli heat-stable enterotoxin b on small intestinal villi in pigs, rabbits and lambs. Veterinary Pathology, v.24, p.71-79, 1987.

REYNOLDS, D.J. et al. Pathology of natural rotavirus infection in clinically normal calves. Research Veterinary Science, v.38, p.264-269, 1985.

RUMESSEN, J.J. Fructose and related food carbohydrates and proteins. Scandinavian Journal of Gastroenterology, v.27, p.819-828, 1992

SAIF, L. et al. Comparative studies of the pathogenesis, antibody immune responses, and homologous protection to porcine and human rotaviruses in gnotobiotic piglets. Advances in Experimental Medicine and Biology, v.412, p.397-403, 1997.
SANTOS, R.L. et al. Dynamics of hematologic and blood chemical changes in Salmonella Typhimurium infected calves. American Journal Veterinary Research, v.63, p.11451150, 2002a.

SANTOS, R.L. et al. Morphologic and Molecular Characterization of Salmonella typhimurium Infection in Neonatal Calves. Veterinary Pathology, v.39, p.200-215, 2002b.

SAVARINO, S.J. et al. Enteroaggregative Escherichia coli heatstable enterotoxin 1 represents another subfamily of $\boldsymbol{E}$. coli heat-stable toxin. Proceedings of the National Academy of Science USA, v.90, p.3093-3097, 1993.

SAVIDGE, T.C. et al. Clostridium difficile toxin B is an inflammatory enterotoxin in human intestine. Gastroenterology, v.125, p.413-420, 2003. Disponível em: $<$ ht tp://linking hub.elsevier.com/retrieve/pii/ S0016508503009028>. Acesso em: 30 mar. 2009. doi: 10.1016/ S0016-5085(03)00902-8

SONGER, J.G.; UZAL, F.A. Clostridial enteric infections in pigs. Journal Veterinary Diagnostic Investigation, v.17, p.528-536, 2005

SPANGLER, B.D. Structure and function of cholera toxin and the related Escherichia coli heat-labile enterotoxin. Microbiology Review, v.56, p.622-647, 1992.

SPILLER, R.C. Role of nerves in enteric infection. Gut, v.51, p.759-762, 2002. Disponível em: <http://gut.bmj.com/cgi/ reprint/51/6/759>. Acesso em: 30 mar. 2009. doi: 10.1136/ gut.51.6.759.

STEGE, H. et al. Prevalence of intestinal pathogens in Danish finishing pig herds. Preventive Veterinary Medicine, v.46, p.279-292, 2000.

SUH, D.K.; SONG, J.C. Prevalence of Lawsonia intracellularis, Brachyspira hyodisenteriae and Salmonella in swine herds. Journal Veterinary Science, v.6, n.4, p.289-293, 2005.

TIEN, X.Y. et al. Activation of the cystic fibrosis transmembrane conductance regulator by cGMP in the human colonic cancer cell line, Caco-2. Journal of Biological Chemistry, v.269, p.51-54, 1994

TSOLIS, R.M. et al. Contribution of Salmonella enterica serovar Typhimuriumvirulence factors to diarrheal disease in calves. Infection and Immunity, v.67, p.4879-4885, 1999.

TURNER, S.M. et al. Weapons of mass destruction: virulence factors of the global killer enterotoxigenic Escherichia coli. FEMS Microbiology Letters, v.263, p.10-20, 2006. Disponível em: <http://www3.interscience.wiley.com/cgi-bin/ fulltext/118603542/PDFSTART>. Acesso em: 30 mar.2009. doi: 10.1111/j.1574-6968.2006.00401.x

VELLENGA, L. et al. Intestinal permeability in pigs during rotavirus infection. American Journal Veterinary Research, v.53, p.1180-1183, 1992.

WADDELL, T.E. et al. Localization of potential binding sites for the edema disease verotoxin (VT2e) in pigs. Canadian Journal Veterinary Research, v.62, p.81-86, 1998. 
WADDELL, T.E.; GYLES, C.L. Sodium deoxycholate facilitates systemic absorption of verotoxin 2e from pig intestine. Infection and Immunity, v.63, p.4953-4956, 1995.

WADDELL, T.E. et al. Interaction of verotoxin 2e with pig intestine. Infection and Immunity, v.64, p.1714-1719, 1996.

WELSH, M.J. et al. Crypts are the site of intestinal fluid and electrolyte secretion. Science, v.218, p.1219, 1982.

WIMER-MACKIN, S. et al. Characterization of receptormediated signal transduction by Escherichia coli type IIa heatlabile enterotoxin in the polarized human intestinal cell line T84. Infection and Immunity, v.69, p.7205-7212, 2001. Disponível em: <http://www.pubmedcentral.nih.gov/ picrender.fcgi?artid=98803\&blobtype $=$ pdf $>$. Acesso em: 30 mar. 2009. doi: 10.1128/IAI.69.12.7205-7212.2001.
WRIGHT, E.M.; LOO, D.D.F. Coupling between $\mathrm{Na}^{+}$, sugar and water. Transport across the intestine. Annual New York Academic Science, v.915, p.54-66, 2000.

WRIGHT, E.M. The intestinal $\mathrm{Na}+/$ glucose cotransporter. Annual Review Physiology, v.55, p.575-589, 1993.

ZACHOS, N.C. et al. Molecular physiology of $\mathrm{Na}^{+} / \mathrm{K}^{+}$exchange. Annual Review Physiology, v.67, p.411-443, 2005.

ZHANG, W. et al. Significance of heat-stable and heat-labile enterotoxins in porcine colibacillosis in an additive model for pathogenicity studies. Infection and Immunity, v.74, n.6, p.31073114, 2006. Disponível em: <http://www.pubmedcentral.nih.gov/ picrender.fcgi?artid $=1479275 \&$ blobtype $=$ pdf $>$. Acesso em: 30 mar. 2009. doi: 10.1128/IAI.01338-05. 